\title{
Salience of stimulus and response features in choice-reaction tasks
}

\author{
T. GILMOUR REEVE \\ Auburn University, Auburn, Alabama \\ ROBERT W. PROCTOR \\ Purdue University, West Lafayette, Indiana \\ DANIEL J. WEEKS \\ Lakehead University, Ontario, Canada \\ and \\ LANIE DORNIER \\ Texas Tech University, Lubbock, Texas
}

\begin{abstract}
A pattern of differential reaction time (RT) benefits obtained in spatial-precuing tasks has been attributed to translation processes that operate on mental codes formed to represent the stimulus and response sets. According to the salient-features coding principle, the codes are based on the salient stimulus and response features, with RTs being fastest when the two sets of features correspond. Three experiments are reported in which the stimulus and response sets were manipulated using Gestalt grouping principles. In the first two experiments, stimuli and responses were grouped according to spatial proximity, whereas in the last experiment, they were grouped according to similarity. With both types of manipulations, the grouping of the stimulus set systematically affected the pattern of precuing benefits. Thus, in these experiments, the organization of the stimulus set was the primary determinant of the features selected for coding the stimulus and response sets in the translation process.
\end{abstract}

Organization of the stimulus display and correspondence of the displayed information with the response controls are important determinants of performance efficiency (e.g., Fitts \& Seeger, 1953; Helander, 1987; Kantowitz, 1982; Wickens, 1984). Considerable research has been conducted on perceptual organization (Pomerantz \& Kubovy, 1986), as well as on the mapping of stimuli to responses (Fitts \& Deininger, 1954; Proctor \& Reeve, 1990; Sanders, 1970), but few studies have examined the relation between the two. The present study provides an investigation of the basic factors involved in the organizational correspondence between stimuli and responses.

Organizational correspondence can be studied from the perspective of the salient-features coding principle (Proctor \& Reeve, 1985; Proctor, Reeve, \& Weeks, 1990; Reeve \& Proctor, 1990). According to this principle, response efficiency is a function of stimulus-response (S-R) translation processes that operate on mental codes formed to represent the stimulus and response sets. These codes

This research was supported in part by U.S. Air Force Office of Scientific Research Grant AFOSR-88-0002. We would like to thank Jim Cauraugh, John Duncan, Lester Krueger, Greg Lockhead, Trammell Neill, and an anonymous reviewer for helpful comments on early drafts of the manuscript. Correspondence concerning this article should be addressed to T. G. Reeve, Motor Behavior Center, Auburn University, AL 36849-5323. are based on the salient features of the respective sets, with responses being fastest and most accurate when the features correspond.

The concept that the mental codes for stimulus and response sets affect performance efficiency in choice-reaction tasks is derived primarily from studies of S-R compatibility (e.g., Fitts \& Deininger, 1954; Fitts \& Seeger, 1953; Kornblum, Hasbroucq, \& Osman, 1990; Proctor \& Reeve, 1990). In a typical two-choice compatibility task, left and right stimuli are assigned to left and right response keys. The compatibility effect is that responses are faster when the assigned stimulus and response locations correspond (e.g., "press left key to left stimulus") than when they do not (e.g., "press right key to left stimulus"), regardless of whether the hands are uncrossed or crossed (e.g., Brebner, Shephard, \& Cairney, 1972). These and other findings indicate that the codes used for translation most often represent the spatial locations of the stimuli and responses (Nicoletti, Umiltá, \& Ládavas, 1984; Umiltá \& Liotti, 1987; Wallace, 1971). However, recent research with two-choice tasks has indicated a hierarchy of coding features on which translation can be based (Heister, Schroeder-Heister, \& Ehrenstein, 1990; Ládavas, 1990).

Much of the initial research from which the salientfeatures coding principle evolved used a four-choice spatial-precuing task (e.g., Miller, 1982; Reeve \& Proc- 
tor, 1984). In that task, which is a variant of the movement-precuing technique (Rosenbaum, 1983), subjects respond to spatial-location stimuli with discrete responses from the index and middle fingers of each hand. The display consists of three horizontal rows in which warning, precue, and target stimuli are presented (see Version 1 of the control display in Table 3). The warning row specifies the four possible response locations, the precue row reduces the four choices to two, and after a variable interval, the target row designates the location in which one of the two responses is to be made.

The primary finding obtained with the spatial-precuing task is a pattern of differential precuing benefits for reaction times (RTs). With a normal, adjacent-hand placement, RTs are fastest when the response locations assigned to a single hand are cued (hand-cued condition), intermediate when the same finger (index or middle) on each hand is cued (finger-cued condition), and slowest when the cued responses differ in terms of both hand and finger (neither-cued condition) (see Reeve \& Proctor, 1984). ${ }^{1}$ However, as is the case for the spatial compatibility effects obtained in two-choice tasks, this pattern of precuing benefits is a function of the spatial features of the stimulus and response sets. When an overlapped-hand placement is used, for which the fingers from each hand are alternated, the precuing benefit is least when the cued responses are from the same hand (but now are on alternate locations) and greatest when they have neither finger nor hand in common (but now are on the two left or two right locations). In other words, responses are faster when the cued locations are consistent with the salient left-right spatial feature of the linear arrangements than when they are not.

The pattern of differential precuing benefits obtained with the spatial-precuing task provides a reliable baseline for examining the effects of organizational manipulations of the stimulus and response sets. Such manipulations, which should modify the features of the sets, can be guided by the Gestalt laws of grouping (e.g., Koffka, 1935/1963; Pomerantz \& Kubovy, 1986; Rock \& Palmer, 1990). In the present experiments, the manipulations involved spatial proximity and similarity. According to the salientfeatures coding principle, the pattern of differential precuing benefits should be altered systematically as a function of the pairings of elements made salient by the organizational manipulations.

In Experiments 1 and 2, the organizational manipulations were of proximity grouping. The spatial locations of the individual elements within the stimulus and response sets were varied to produce different groupings that emphasized distinct pairs of locations. In Experiment 3, organization was manipulated by similarity grouping. The elements composing the stimulus set, as well as the placements of fingers from the hands, were varied to emphasize distinct pairs of locations. For all experiments, the critical test was the effect of the organizational manipulations on the pattern of differential precuing benefits.

\section{EXPERIMENT 1 \\ Spatial Correspondence Between the Stimulus and Response Sets}

One method for varying the organizational correspondence of the stimulus and response sets is to manipulate the spatial relations between the sets. Fitts and Seeger (1953) performed such a manipulation in their initial work on S-R compatibility. They used three configurations of spatial-location stimuli and three similar configurations of response locations, resulting in nine different pairings of stimulus and response sets. Responses were fastest and most accurate for the three pairings in which the stimulus and response sets were configured similarly. In other words, performance was best when the stimulus and response sets had a direct spatial correspondence. Although these results show that performance is degraded when the configurations of the stimulus and response sets do not correspond, they do not indicate whether such degradation occurs when the relative locations of stimuli and responses correspond but absolute locations do not.

Reeve and Proctor (1985) compared RTs from two experiments (Experiments 1 and 3, Reeve \& Proctor, 1984) using horizontal arrangements of equally spaced stimuli assigned to horizontal arrangements of responses that differed in the specific placement of the hands. In one experiment, the hands were placed on adjacent keys in the center of the keyboard, and thus the spatial positioning corresponded closely to that of the equally spaced display. In the other experiment, the hands were placed at the ends of the keyboard. Thus, although the assignment of stimuli to responses was direct in terms of relative locations, the response arrangement had a large, central gap that was not present in the display. RTs were faster overall in the former experiment than in the latter, suggesting that RTs benefit from absolute spatial correspondence.

Experiment 1 provided a more thorough examination of the roles of absolute and relative spatial correspondence by manipulating proximity of the elements in the stimulus and response arrangements. The horizontal arrangements were similar to those from previous studies (e.g., Reeve \& Proctor, 1984). However, the absolute spatial characteristics of the sets were manipulated factorially. Two spatial arrangements, "together" and "separated," were used for both the stimulus and response sets (see Figure 1). The together arrangements used four equally spaced locations, whereas the separated arrangements used two locations to the left and two to the right of a large, central gap. Responding should be fastest overall for conditions in which the stimulus and response organizations correspond. Moreover, if separating the two halves of the arrangements increases the salience of the left-right feature, then the advantage for the left-right precues relative to the other precue conditions should increase. 

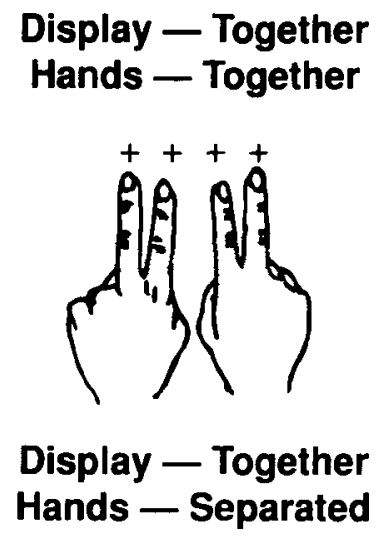

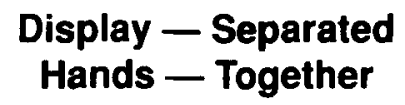

$++$

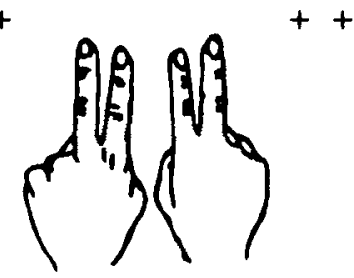

Display - Separated
Hands - Separated

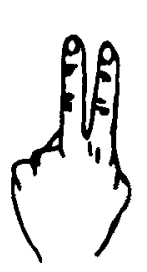

$+++$
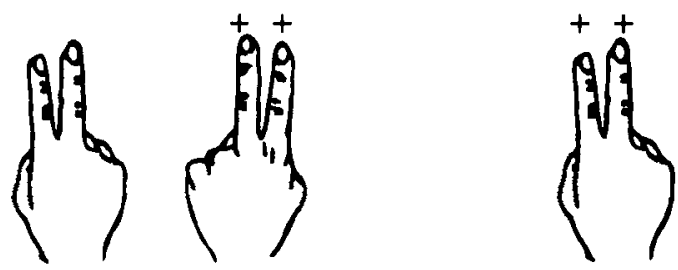

Figure 1. Spatial arrangements for stimulus and response sets in Experiment 1.

\section{Method}

Apparatus and Stimuli. The stimuli were presented on the display screen of a microcomputer and were viewed from a distance of approximately $50 \mathrm{~cm}$. The stimulus display for each trial consisted of a warning stimulus, a precue stimulus, and a target stimulus, with the entire display centered on the viewing screen. The warning stimulus was a row of four plus signs, each of which was approximately $3 \mathrm{~mm}$ square. For the together display, a blank space of $6 \mathrm{~mm}$ separated each sign in the row, making the total visual angle subtended by the row approximately $3.43^{\circ}$. The spacing was similar for the separated display, with the exception that the two central signs were separated by a large 6 $6 \mathrm{~cm}$ space, making the visual angle of the row approximately $9.54^{\circ}$. The precue occurred immediately below the warning stimulus and consisted of plus signs either in all four locations or in only two locations. The target was a single sign that occurred immediately below one of the cued locations. The warning, precue, and target rows each were separated by $5 \mathrm{~mm}$. Thus, the vertical extent of the displays was approximately $2.18^{\circ}$.

Responses were made by pressing one of four permissible keys on the computer keyboard. When the hands were together, the fingers were situated on the four center keys on the bottom row of the keyboard (the V, B, N, and M keys). When the hands were separated, the fingers were situated on the two keys to each side of the four center keys (the X, C, and ,, . keys). The full left to right extent of the four response keys was $7 \mathrm{~cm}$ for the together arrangement and $13 \mathrm{~cm}$ for the separate arrangement. A large central gap of $7.5 \mathrm{~cm}$ separated the two inner keys when the hands were separated.

The subject's task was to indicate the position in which the target occurred by making a discrete finger response with either the left middle, left index, right index, or right middle finger. Four precuing conditions comparable to those from previous studies were used (Proctor \& Reeve, 1988; Reeve \& Proctor, 1984). These conditions differed in terms of the responses indicated by the precue. For the uncued condition, the precue contained all four signs, and the target occurred in one of the four locations. For the three cued conditions, the precue contained only two characters, and the tar- get occurred in one of these two locations. In the hand-cued condition, the precue indicated the two locations assigned to either the left hand (the two leftmost locations) or right hand (the two rightmost locations). In the finger-cued condition, the precue specified the two locations assigned to either the index fingers (the two inner locations) or middle fingers (the two outer locations). In the neither-cued condition, the precue indicated locations assigned to the index finger for one hand and the middle finger for the other hand (the two pairs of alternate locations).

In addition to the type of precue, the interval between precue onset and target onset was varied. The precuing intervals were 0 (i.e., simultaneous onset of the precue and target), .375, .75, 1.5, and $3.0 \mathrm{sec}$, to encompass the range that has been shown to be critical in our earlier work (Reeve \& Proctor, 1984). An experimental session had 310 trials. The first 30 trials were considered practice, and the data from these trials were not analyzed. The remaining 280 trials included $\mathbf{4 0}$ for the uncued condition and $\mathbf{8 0}$ for each of the three cued conditions. Each cue-target combination was presented equally often for the five precuing intervals. Precuing condition and interval were manipulated within subjects and varied randomly from trial to trial. Four orders of trials were used, counterbalanced across subjects. These cue conditions, intervals, and trial orders were the same as those used in Reeve and Proctor (1984).

Subjects and Procedure. Thirty-two students from Auburn University participated in two sessions each for extra credit in an introductory psychology course. Response organization (separated, together; see Figure 1) was manipulated between subjects. Sixteen subjects performed with the hands together, and 16 with the hands separated. Display organization (separated, together; see Figure 1) was manipulated within subjects in each hand condition. Half of the subjects were tested with the together display in a first session and the separated display in a second session; this order was reversed for the other half of the subjects.

\section{Results}

Mean RT and percentage of errors (PE) were obtained as a function of precue, interval, response organization, 


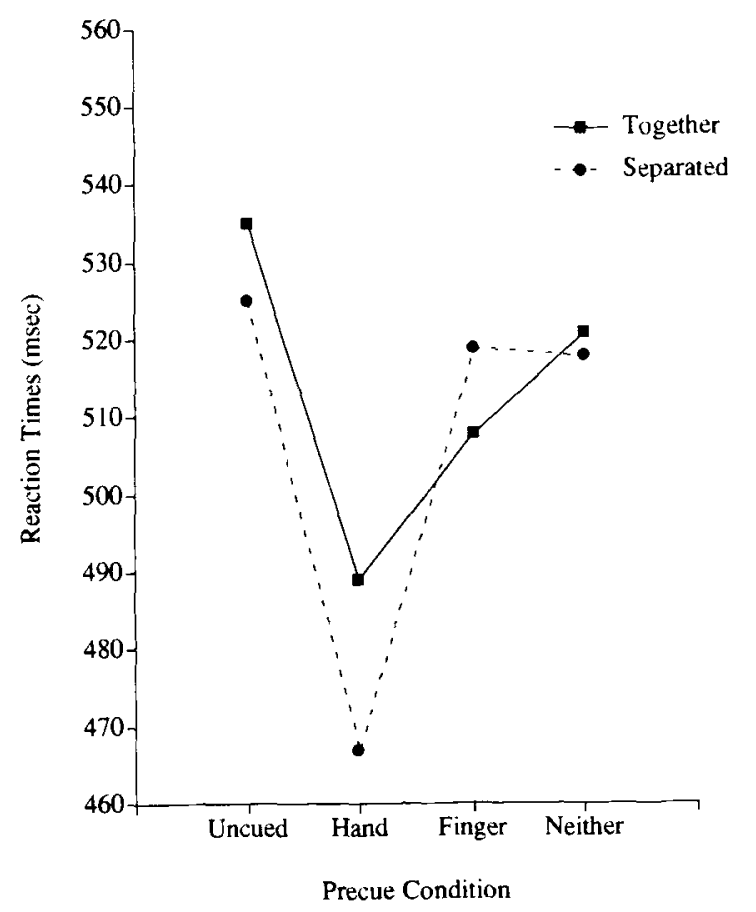

Figure 2. Mean RTs as a function of precue and display organization in Experiment 1.

and display organization. RTs less than $200 \mathrm{msec}$ or greater than $2,000 \mathrm{msec}(<1 \%)$ were excluded from this experiment and subsequent analyses.

Reaction times. The effects of interval $[F(4,120)=$ $88.2, p<.001]$, precue $[F(3,90)=39.6, p<.001]$, and interval $\times$ precue $[F(12,360)=5.41, p<.001]$, were significant. The precue main effect is primarily a function of responses being fastest for the hand-cued condition ( $M=478 \mathrm{msec})$, intermediate for the finger-cued and neither-cued conditions $(M \mathrm{~s}=514$ and $518 \mathrm{msec}$, respectively), and slowest for the uncued condition ( $M=$ $530 \mathrm{msec}$ ). The interval effect reflects a decrease in RT as the precuing interval increased $(M \mathrm{~s}=583,509,513$, 490 , and $487 \mathrm{msec}$ for the intervals of $0, .375, .75,1.5$, and $3.0 \mathrm{sec}$, respectively). The interaction is due to the advantage for the cued conditions, relative to the uncued condition, increasing across precuing intervals. All three of these effects customarily are obtained with the precuing procedure (e.g., Cauraugh, 1990; Cauraugh \& Horrell, 1989; Proctor \& Reeve, 1986, 1988; Reeve \& Proctor, 1984). They also are present in the remaining experiments described in this article, but will not be discussed in detail.

The only other significant term was the display organization $\times$ precue interaction $[F(3,90)=8.79, p<.001]$. As is apparent in Figure 2, the interaction primarily reflects a change in the $\mathrm{R}^{\prime} \mathrm{T}$ pattern for the hand-cued and finger-cued conditions. For the together display, the pattern of RTs was similar to that typically obtained in the precuing studies (e.g., Cauraugh, 1990; Proctor \& Reeve, 1988): RTs were fastest for the hand-cued condition, in- termediate for the finger-cued condition, and slowest for the neither-cued condition. In contrast, for the separated display, the difference typically found between the fingercued and the neither-cued conditions was eliminated, and the difference between the hand-cued and finger-cued conditions was enhanced. Thus, separating the display had the effect of equating the two conditions for which precues designated locations on both sides of the display.

Error rates. The main effect of precue was significant $[F(3,90)=4.01, p<.01 ; \mathrm{PE}=2.0 \%$ for the uncued conditions, $2.2 \%$ for the hand-cued and finger-cued conditions, and $2.7 \%$ for the neither-cued condition], as was the precue $\times$ interval interaction $[F(12,360)=3.84$, $p<.001]$. This interaction is a function of the PE reaching a maximum at a shorter interval for the precued conditions than for the uncued condition. Also, the display organization $\times$ response organization interaction was marginally significant $[F(1,30)=3.51, p=.07]$ and the three-way interaction of those variables with precue was significant $[F(3,90)=4.84, p<.01]$. These interactions are shown in Table 1 . With the exception of the hand-cued condition, PE was greater when the display and response organizations did not correspond.

\section{Discussion}

The manipulation of the spatial characteristics of the S-R sets produced two different patterns of RTs. The typical pattern of differential precuing benefits was obtained for both the together and separated response arrangements with the together display (i.e., responding was fastest for the hand-cued condition, intermediate for the finger-cued condition, and slowest for the neither-cued condition). Also, with the together display, RTs were slower with the hands apart $(M=530 \mathrm{msec})$ than with the hands together ( $M=494 \mathrm{msec})$. Although this difference was not significant, the tendency for slower RT when the hands were separated is consistent with our previous betweenexperiment comparison (Reeve \& Proctor, 1985). In both the present experiment and the previous comparison, the more direct spatial correspondence between the stimulus and response sets tended to produce faster RTs.

The pattern of precuing benefits obtained with the separated display was distinct from that obtained with the together display. For the separated display, the RTs for the finger-cued and neither-cued conditions did not differ, and

Table 1

Display Organization $\times$ Response Organization $\times$ Precue Interaction for Percentages of Errors in Experiment 1.

\begin{tabular}{lcccc}
\hline \multirow{2}{*}{$\begin{array}{c}\text { Response } \\
\text { Organization }\end{array}$} & \multicolumn{4}{c}{ Precue } \\
\cline { 2 - 5 } & Uncued & Hand & Finger & Neither \\
Together & \multicolumn{2}{c}{ Display } & Together \\
Separated & 1.5 & 3.1 & 1.6 & 2.5 \\
\multicolumn{5}{c}{} \\
Together & 2.7 & 2.7 & 2.5 & 2.8 \\
Separated & 2.2 & 1.5 & 2.5 & 3.3 \\
\hline
\end{tabular}


the difference in RTs between the hand-cued and fingercued conditions was enhanced. In other words, separating the stimulus set eliminated the precuing benefit for the inner-outer locations (the finger-cued condition) relative to the alternate locations (the neither-cued condition). Thus, the results of Experiment 1 indicate that the pattern of precuing benefits and the overall level of RTs are functions of the organizational correspondence between the stimulus and response sets.

The unique pattern of precuing benefits obtained with the separated display could be attributed to stimulusidentification processes, rather than to translation processes. Separating the display may have hampered identification of the precues that contained an element on each side (the finger-cued and neither-cued conditions). Evidence against this identification account is provided by a comparison of the RTs for the subjects in the separated-hand placement. With the separated stimulus display, the RTs for the finger-cued and neither-cued conditions were $519 \mathrm{msec}$ and $524 \mathrm{msec}$, respectively, whereas for the together display, the RTs for the two conditions were $524 \mathrm{msec}$ and $539 \mathrm{msec}$, respectively. Thus, the RTs were slightly faster with the separated display, even though the precued locations came from different sides of the stimulus display.

\section{EXPERIMENT 2}

\section{Partitioning the Stimulus Set}

Experiment 1 indicated that spatial correspondence is an important factor in coding the stimulus and response sets. To test this notion further, Experiment 2 included a partition of the stimulus set that spatially grouped the inner locations separately from the outer locations. When proximity grouping favors the two inner and two outer locations, the distinction between these pairs of locations should be increased. Consequently, the benefit for the finger-cued condition, in which these pairs of locations are precued, should increase relative to the benefits for the other precue conditions.

\section{Method}

Three types of displays were used: (1) the together display $(++++) ;(2)$ the separated display $(++++)$; and (3) a partitioned display $(t+++)$. For the partitioned display, the two outer stimulus locations were the same as those for the separated display and the two inner locations were the same as those for the together display. Thus, the outer and inner stimulus locations were separated by two 3-cm gaps, one for the leftmost pair of stimuli and one for the rightmost pair. Forty-eight students from Auburn University who had not participated in Experiment 1 were tested, 16 with each display. All subjects performed with the fingers on the $V, B, N$, and $M$ keys (the hands-together position used in Experiment 1). All other methods were the same as those used in Experiment 1.

\section{Results}

Reaction times. RTs showed effects of interval $[F(4,180)=135.3, p<.001]$, precue $[F(3,135)=$ $26.42, p<.001]$, and their interaction $[F(12,540)=$

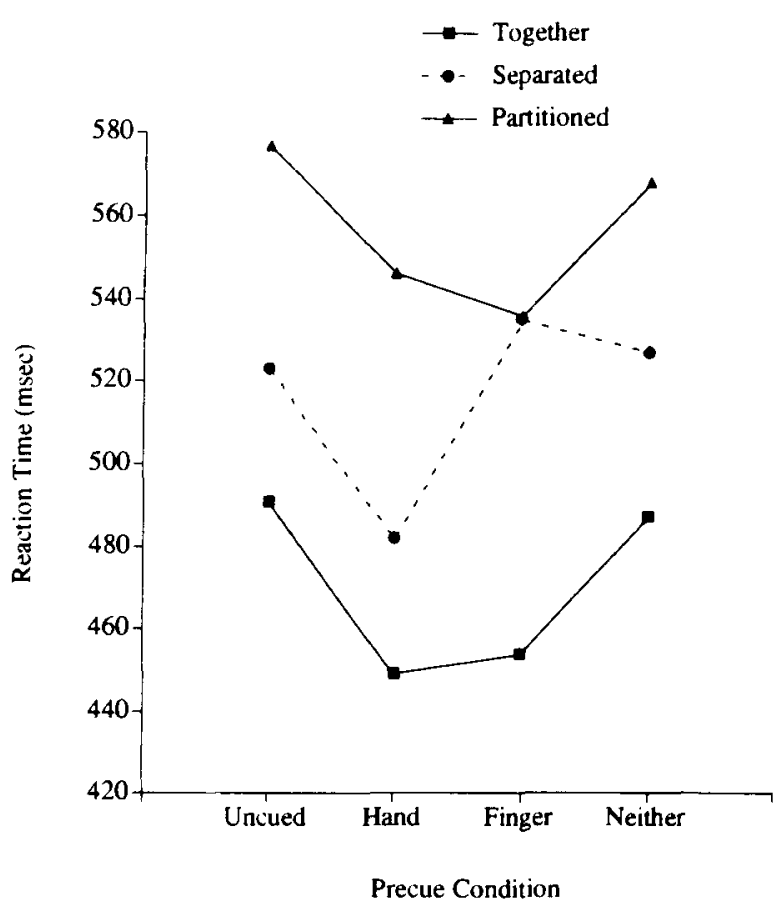

Figure 3. Mean RTs as a function of precue and display organization in Experiment 2.

$7.42, p<.001]$, replicating again the results from similar precuing studies (e.g., Reeve \& Proctor, 1984). In addition, the interaction of precue $\times$ display organization was significant $[F(6,135)=6.28, p<.001]$. The together display produced the typical precuing benefit for the hand-cued condition, and this benefit was enhanced for the separated display (see Figure 3). These results replicate the RT patterns from Experiment 1.

In contrast, with the partitioned display, the precuing benefit was greatest for the finger-cued condition (see Figure 3). It should be emphasized that this latter pattern of benefits has not been obtained in previous studies (Cauraugh, 1990; Cauraugh \& Horrell, 1989; Miller, 1982; Proctor \& Reeve, 1988; Reeve \& Proctor, 1984). Therefore, it seems to be a unique function of the grouping of the partitioned display, which distinguishes the locations associated with the index fingers from those associated with the middle fingers.

Error rates. The error data showed only a significant interaction of precue $\mathrm{x}$ interval $[F(12,540)=3.43$, $p<.001]$. As shown in Table 2 , the data are relatively noisy and unsystematic.

\section{Discussion}

For the together display, the usual pattern of differential precuing benefits for RTs was obtained. Moreover, the separated display showed convergence of the fingercued and neither-cued conditions similar to that found in Experiment 1. A third pattern of benefits was produced with the partitioned display, which was organized to emphasize the inner-outer feature. For the partitioned 
Table 2

The Precue $\times$ Interval Interaction for Percentages of Errors in Experiment 2

\begin{tabular}{lccccc} 
& \multicolumn{5}{c}{ Interval (in sec) } \\
\cline { 2 - 6 } \multicolumn{1}{c}{ Precue } & $\mathbf{0}$ & .375 & .75 & 1.5 & 3.0 \\
\hline Uncued & 2.3 & 4.2 & 2.6 & 2.6 & 5.2 \\
Hand-cued & 1.0 & 4.8 & 2.9 & 2.9 & 2.6 \\
Finger-cued & 5.3 & 4.3 & 3.5 & 1.2 & 1.6 \\
Neither-cued & 4.6 & 3.4 & 4.3 & 4.3 & 3.6 \\
\hline
\end{tabular}

display, RTs tended to be fastest for the finger-cued condition, in which the precues were consistent with the inner-outer organizational feature. In sum, the pattern of precuing benefits is a function of the spatial organization of the stimulus set. Each of the three patterns of precuing benefits is associated with a specific display organization.

\section{EXPERIMENT 3}

\section{Similarity Grouping of the Stimulus Set}

In Experiment 3, organization of the stimulus set was manipulated by the Gestalt principle of similarity grouping of the elements (Pomerantz \& Kubovy, 1986). The stimulus display was a modification of the equally spaced, horizontal arrangement. The four locations were indicated either by " +" or " 0 " characters. In the control displays, the same character was used for all four locations. In the experimental displays, two instances of each of the characters designated the four locations, thus allowing pairs of locations that share a common character to be grouped. In addition to an adjacent-hand placement (the handstogether position from Experiments 1 and 2), the experiment included the overlapped placement used in previous studies to dissociate fingers from locations (Cauraugh, 1990; Cauraugh \& Horrell, 1989; Proctor \& Reeve, 1988; Reeve \& Proctor, 1984). For this latter placement, the hands were overlapped such that the fingers from each hand were alternated on the response locations.

Because the left-right spatial feature is emphasized for the horizontal stimulus and response arrangements, the benefit for precuing the left or right pairs of locations should be obtained for all displays and hand placements. For the displays in which the similarity grouping emphasizes another feature (e.g., the inner-outer locations), comparable benefits should occur for the precued pairs of locations consistent with that feature.

\section{Method}

The subjects were 128 students enrolled at Auburn University who had not participated in the previous experiments. Sixty-four were tested with the adjacent-hand placement, and 64 with the overlapped-hand placement. For this latter placement, the left-toright ordering of fingers was right index, left middle, right middle, and left index. Within each of these hand-placement groups, 16 subjects were tested with each of the four display organizations: (1) the control display, for which all four stimulus elements were the same (either " + " or " "o" signs); (2) the left-right display, for which the two leftmost elements were of one type and the two rightmost elements of the other; (3) the inner-outer display, for which the two inner and two outer elements were of different types; and
(4) the alternate display, for which alternate elements differed in type. For all display organizations, half of the subjects received Version 1 and half Version 2 (see Table 3), for which the locations of the + and o elements were reversed. The manipulations of precuing condition and interval were the same as in Experiments 1 and 2.

\section{Results}

Reaction times. The RT data showed main effects of precue $[F(3,360)=26.7, p<.001]$ and interval $[F(4,480)=359.4, p<.001]$ as well as a precue $\times$ interval interaction $[F(12,1344)=12.0, p<.001]$. The main effect of hand placement was significant $[F(1,120)=117.3, p<.001]$, with responses being slower for the overlapped placement $(M=693 \mathrm{msec})$ than for the adjacent placement $(M=512 \mathrm{msec})$, as customarily obtained (e.g., Reeve \& Proctor, 1984). Hand placement interacted with precue $[F(3,360)=19.4$, $p<.001]$ and with precue and interval $[F(12,1344)=$ $3.07, p<.001]$.

The hand placement $\times$ precue interaction replicates the finding of Reeve and Proctor (1984) that the precuing benefits are determined by the spatial locations. For both hand placements, RTs were slowest for the uncued condition $(M \mathrm{~s}=533$ and $711 \mathrm{msec}$ for the adjacent and overlapped placements, respectively). However, the ordering of the precued conditions was different for the adjacent placement than for the overlapped placement. The means for the hand-cued, finger-cued, and neither-cued conditions were 488,507 , and $521 \mathrm{msec}$ with the adjacent placement, and 699,686 , and $676 \mathrm{msec}$ with the overlapped placement. Because the pairs of locations that correspond to the hand-cued and neither-cued conditions are switched for the two hand placements, the RTs are ordered consistently by the precued spatial locations and not by the specific response fingers. The three-way interaction with interval is a function of the differences between the prepared conditions being evident primarily at the shorter intervals.

The only significant effect of display organization was the main effect $[F(3,120)=2.90, p<.05]$. Responses were slower for the control display $(M=626 \mathrm{msec})$ and the alternate display $(M=624 \mathrm{msec})$ than for the left-right display ( $M=592 \mathrm{msec})$ and the inner-outer

Table 3

Example Displays for Experiment 3, with a Precue Indicating the Two Leftmost Locations and the Target Indicating the Leftmost Response Location

\begin{tabular}{|c|c|c|c|c|}
\hline \multirow[b]{2}{*}{ Stimuli } & \multicolumn{3}{|c|}{$++\infty$ Display } & \multirow[b]{2}{*}{ Alternate } \\
\hline & Control & Left-Right & Inner-Outer & \\
\hline \multicolumn{5}{|c|}{ Version 1} \\
\hline Warning & $+t+t$ & $++\infty o$ & toot & $+o+o$ \\
\hline Precue & ++ & ++ & $+o$ & to \\
\hline Target & + & + & + & + \\
\hline \multicolumn{5}{|c|}{ Version 2} \\
\hline Warning & 0000 & oot t & $0++0$ & $0+0+$ \\
\hline Precue & 00 & 00 & $o+$ & $0+$ \\
\hline Target & o & o & o & o \\
\hline
\end{tabular}


Table 4

Mean RTs (in msec) as a Function of Display Organization, Precue, and Hand Placement in Experiment 3

\begin{tabular}{lcccc}
\hline & \multicolumn{4}{c}{ Display Organization } \\
\cline { 2 - 4 } Precue & Control & Left-Right & Inner-Outer & Alternate \\
\cline { 3 - 5 } Uncued & 560 & 515 & 501 & 556 \\
Hand & 511 & 470 & 454 & 517 \\
Finger & 540 & 498 & 462 & 526 \\
Neither & 553 & 511 & 476 & 542 \\
& & Overlapped-Hand Placement & \\
Uncued & 729 & 690 & 680 & 744 \\
Hand & 720 & 704 & 662 & 711 \\
Finger & 703 & 683 & 648 & 709 \\
Neither & 696 & 664 & 656 & 686 \\
\hline
\end{tabular}

display $(M=567 \mathrm{msec})$. Although display organization did not interact significantly with precue condition, the patterns of RTs for the respective displays appear to differ. For the alternate display, the precuing benefit for each of the precued conditions was comparable to that for the control. However, for the left-right and inner-outer displays, the inner-outer display seemed to provide an added precuing advantage for both the inner-outer and alternate locations relative to the precuing advantage provided by the left-right display (see Table 4).

To further evaluate this apparent difference, a follow-up analysis was performed between the left-right and innerouter displays. This analysis showed a marginally significant interaction of display organization $\times$ precue $x$ hand placement $[F(3,180)=2.46, p=.06]$. The interaction was as follows. With the adjacent-hand placement, the two display organizations had small differences for the uncued (14 msec) and hand-cued (16 msec) conditions. However, for both the finger-cued and neithercued conditions, responses were approximately $35 \mathrm{msec}$ faster with the inner-outer display than with the left-right display. A similar benefit of the inner-outer display was obtained with the overlapped placement, for which the smaller differences occurred for the uncued $(10 \mathrm{msec})$ and the neither-cued ( $8 \mathrm{msec}$ ) conditions. However, for both the finger-cued and hand-cued conditions, responses were $35 \mathrm{msec}$ and $42 \mathrm{msec}$ faster, respectively, with the innerouter display than with the left-right display. Thus, for both hand placements, the inner-outer display increased the benefits for the precue conditions that corresponded to the inner-outer and alternate locations.

Error rates. The analysis of errors showed main effects of precue $[F(3,360)=19.1, p<.001]$, hand placement $[F(1,120)=13.0, p<.001]$, and interval $[F(4,480)$ $=3.64, p<.01]$. More errors were made (1) for the precued conditions (PEs $=4.9 \%, 5.2 \%$, and $5.7 \%$ for the hand-cued, finger-cued, and neither-cued conditions, respectively) than for the uncued condition ( $\mathrm{PE}=3.0 \%$ ), (2) with the overlapped placement $(\mathrm{PE}=6.6 \%$ ) than with the adjacent placement $(\mathrm{PE}=2.9 \%)$, and $(3)$ at the .375 and .75 -sec precue intervals than at the other intervals (PEs $=4.5 \%, 5.4 \%, 4.9 \%, 4.3 \%$, and $4.5 \%$ for the intervals of $0, .375, .75,1.5$, and $3.0 \mathrm{sec}$, respectively).
Additionally, the two-way interactions of hand placement $\times$ precue $[F(3,360)=12.6, p<.001]$ and hand placement $\times$ interval $[F(4,480)=2.03, p<.025]$ were significant. The former interaction is a function of the error rates being elevated in the prepared conditions for the overlapped placement ( $\mathrm{PE}=7.6 \%$ ) relative to the adjacent placement $(\mathrm{PE}=3.0 \%)$. The latter interaction is due to error rates for the adjacent placement decreasing from the .375 -sec interval onward, whereas for the overlapped placement they did not. No terms involving display organization were significant in the error analysis.

\section{Discussion}

The manipulation of similarity grouping had little effect when it involved the alternate locations. However, when the display grouped either the left-right or innerouter locations by similarity, RTs were faster overall. Moreover, the inner-outer grouping also provided an additional benefit for the conditions that used the inner-outer and alternate precue locations. For both the adjacent and overlapped placements, these precue locations had faster RTs with the inner-outer grouping than with the left-right grouping. Thus, similarity grouping apparently provided another feature for coding that was beneficial when it emphasized locations that are not typically salient.

\section{GENERAL DISCUSSION}

When pairs of responses from the middle and index fingers of the two hands are precued, a pattern of differential precuing benefits is obtained (Reeve \& Proctor, 1984): RTs are fastest when the two leftmost and rightmost locations are cued and slowest when alternate locations are cued. This pattern of precuing benefits has been attributed to translation processes operating on spatial codes used to represent the stimulus and response sets (Cauraugh, 1990; Cauraugh \& Horrell, 1989; Proctor \& Reeve, 1986, 1988; Reeve \& Proctor, 1984, 1985). The explanation for the pattern, in terms of the salient-features coding principle (Proctor \& Reeve, 1986), is that translation of the precue stimulus into a subset of cued responses occurs most rapidly when the precue is consistent with the salient left-right feature of the stimulus and response arrangements.

If relative salience is the critical factor determining the pattern of differential precuing benefits, then it should be possible to alter the pattern systematically by making other features salient. In Experiments 1 and 2, the Gestalt organizational principle of spatial proximity was used to vary the structure of the sets. Consistent with the salientfeatures perspective, pairs of stimulus locations grouped by spatial proximity benefited more from being precued than did pairs that were incongruent with the proximity grouping.

Manipulations of similarity grouping were examined in Experiment 3. Performance was improved overall when similarity grouping was consistent with either the left-right or inner-outer distinction. In addition, similarity grouping for the inner-outer distinction produced rela- 
tively greater precuing benefits for the conditions assigned to the inner-outer and alternate locations. However, little effect on RTs was apparent when similarity grouping corresponded with the alternate locations of the linear arrays.

Although both proximity grouping and similarity grouping affected performance, they seemed to do so in different ways. Similarity grouping was effective only when it corresponded with spatial organizing features (i.e., left-right or inner-outer). In contrast, proximity grouping apparently determined the spatial features. Thus, even though these two types of grouping manipulations are members of a single category of lawful perceptual organization, their impact in choice-reaction tasks may not be equivalent.

In conclusion, the present study confirms that manipulating the organization of the stimulus and response sets influences performance in a manner consistent with the perspective of salient-features coding. Moreover, the most effective manipulations were linked to features of the stimulus set. Proximity grouping of the response set in Experiment 1 had little apparent effect on the pattern of RTs, nor did the manipulation of overlapped versus adjacent placement in Experiment 3. Although the manipulations of the response set used in the present experiments were relatively ineffective, other manipulations could be more effective. We previously have shown that the precuing benefits are enhanced when the hand distinction is made more salient by turning the hands inward for placement on a column of response keys (Proctor \& Reeve, 1986). Whether other aspects of the response set can influence the coding and in what situations remains to be determined.

\section{REFERENCES}

Brebner, J., Shephard, M., \& Cairney, P. (1972). Spatial relationships and S-R compatibility. Acta Psychologica, 36, 1-15.

Cauraugh, J. H. (1990). Speed-accuracy trade off during response preparation. Research Quarterly for Exercise \& Sport, 61, 331-337.

Cauraugh, J. H., \& Horrell, J. F. (1989). Advanced preparation of discrete finger responses: Nonmotoric evidence. Acta Psychologica, 72, 117-138.

FitTs, P. M., \& Deininger, R. L. (1954). S-R compatibility: Correspondence among paired elements within stimulus and response codes. Journal of Experimental Psychology, 48, 483-492.

FitTs, P. M., SeEger, C. M. (1953). S-R compatibility: Spatial characteristics of stimulus and response codes. Journal of Experimental Psychology, 46, 199-210.

Heister, G., Schroeder-Heister, P., \& Ehrenstein, W. H. (1990). Spatial coding and spatio-anatomical mapping: Evidence for a hierarchical model of spatial stimulus-response compatibility. In R. W. Proctor \& T. G. Reeve (Eds.), Stimulus-Response Compatibility: An integrated perspective (pp. 117-143). Amsterdam: North-Holland.

Helander, M. G. (1987). Design of visual displays. In G. Salvendy (Ed.), Handbook of human factors (pp. 507-548). New York: Wiley.

KANTOWITZ, B. H. (1982). Interfacing human information processing and engineering psychology. In W. C. Howell \& E. A. Fleishman (Eds.), Human performance and performance productivity (Vol. 2, pp. 31-81). Hillsdale, NJ: Erlbaum.

KoffKA, K. (1963). Principles of Gestalt psychology. New York: Harcourt, Brace, \& World. (Original work published 1935)
Kornblum, S., Hasbrouce, T., Osman, A. (1990). Dimensional overlap: Cognitive basis for stimulus-response compatibility-A model and taxonomy. Psychological Review, 97, 253-270.

LÁdAVAs, E. (1990). Some aspects of spatial stimulus-response compatibility in adults and normal children. In R. W. Proctor \& T. G. Reeve (Eds.), Stimulus-response compatibility: An integrated perspective (pp. 145-162). Amsterdam: North-Holland.

Millek, J. (1982). Discrete versus continuous stage models of humaninformation processing: In search of partial output. Journal of $E x-$ perimental Psychology: Human Perception \& Performance, 11, 221-233.

Nicoletti, R., Umilta, C., \& Ladavas, E. (1984). Compatibility due to the coding of the relative position of the effectors. Acta Psychologica, 57, 133-143.

Pomerantz, J. R., \& Kubovy, M. (1986). Theoretical approaches to perceptual organization. In K. R. Boff, L. Kaufman, \& J. P. Thomas (Eds.), Handbook of perception and human performance (Vol. 2, pp. 36-1 - 36-46). New York: Wiley.

Proctor, R. W., \& ReEve, T. G. (1985). Compatibility effects in the assignment of symbolic stimulus to discrete finger responses. Journal of Experimental Psychology: Human Perception \& Performance, 11, 623-639.

Proctor, R. W., \& Reeve, T. G. (1986). Salient features coding operations in spatial precuing tasks. Journal of Experimental Psychology: Human Perception \& Performance, 12, 277-285.

Proctor, R. W., \& ReEve, T. G. (1988). The acquisition of taskspecific productions and modification of declarative representations in spatial-precuing tasks. Journal of Experimental Psychology: General, 117, 182-196.

Proctor, R. W., \& ReEve, T. G. (1990). Stimulus-response compatibility: An integrated perspective. Amsterdam: North-Holland.

Proctor, R. W., Reeve, T. G., We Weks, D. J. (1990). A triphasic approach to the acquisition of response-selection skill. In G. H. Bower (Ed.), The psychology of learning and motivation (Vol. 26, pp. 207240). San Diego, CA: Academic Press.

ReEve, T. G., \& Proctor, R. W. (1984). On the advance preparation of discrete finger responses. Journal of Experimental Psychology: Human Perception \& Performance, 10, 541-553.

ReEVe, T. G., \& PRoctor, R. W. (1985). Nonmotoric translation processes in the preparation of discrete finger responses. Journal of $E x-$ perimental Psychology: Human Perception \& Performance, 11, 234-241.

Reeve, T. G., \& Proctor, R. W. (1990). The salient-features coding principle for spatial- and symbolic-compatibility effects. In $R$. W. Proctor \& T. G. Reeve (Eds.), Stimulus-response compatibility: An integrated perspective (pp. 163-180). Amsterdam: North-Holland.

Rock, I., PALMER, S. (1990). The legacy of Gestalt psychology. Scientific American, 263(6), 84-90.

Rosenbaum, D. A. (1983). The movement precuing technique: Assumptions, applications, and extensions. In R. A. Magill (Ed.), Memory and control of action (pp. 231-274). Amsterdam: North-Holland.

SANDERS, A. F. (1970). Some variables affecting the relation between relative signal frequency and choice RT. Acta Psychologica, 33, 45-55.

UMILTÁ, C., \& LIOTTI, M. (1987). Egocentric and relative spatial codes in S-R compatibility. Psychological Research, 49, 81-90.

WALLACE, R. J. (1971). S-R compatibility and the idea of the response code. Journal of Experimental Psychology, 88, 354-360.

WICKENS, C. D. (1984). Engineering psychology and human performance. Columbus, $\mathrm{OH}$ : Charles E. Merrill.

\section{NOTE}

1. In previous precuing studies (e.g., Cauraugh, 1990; Miller, 1982; Reeve \& Proctor, 1984), the cued conditions were labeled "prepared:hand," "prepared:finger," and "prepared:neither." These conditions are the same as the hand-cued, finger-cued, and neither-cued conditions in the present study.

(Manuscript received September 25, 1991; revision accepted for publication April 26, 1992.) 